\title{
Article
}

\section{Exploring action learning for academic development in research intensive settings}

Stocks, Claire, Trevitt, Chris and Hughes, Joseph

Available at https://clok.uclan.ac.uk/21075/

Stocks, Claire orcid iconORCID: 0000-0003-2066-4325, Trevitt, Chris and Hughes, Joseph (2018) Exploring action learning for academic development in research intensive settings. Innovations in Education and Teaching

International, 55 (2). pp. 123-132. ISSN 1470-3297

It is advisable to refer to the publisher's version if you intend to cite from the work.

http://dx.doi.org/10.1080/14703297.2017.1417886

For more information about UCLan's research in this area go to http://www.uclan.ac.uk/researchgroups/ and search for < name of research Group>.

For information about Research generally at UCLan please go to http://www.uclan.ac.uk/research/

All outputs in CLoK are protected by Intellectual Property Rights law, including Copyright law. Copyright, IPR and Moral Rights for the works on this site are retained by the individual authors and/or other copyright owners. Terms and conditions for use of this material are defined in the policies page.

\section{CLoK}

Central Lancashire online Knowledge www.clok.uclan.ac.uk

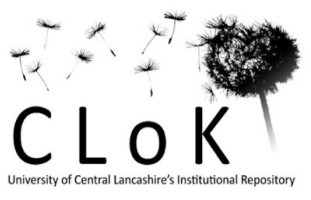




\section{Exploring Action Learning for Academic Development in Research Intensive Settings}

2 Dr. Claire Stocks (University of Central Lancashire), Dr. Chris Trevitt (Australian National University)

3 and Dr. Joseph Hughes (Australian National University)

\section{Abstract}

5 The potential of action learning (AL) for academic development has not received a lot of attention.

6 Building from two case studies in which AL has been used in different ways in research-intensive

7 universities in Australia and the UK, we suggest that the approach may be of benefit to developers in

8 the changing landscape in which they are expected to function. The opportunities for and challenges

9 of leadership for AL in educational development, particularly involving non-academic staff, are also

10 briefly explored. We argue that AL offers a way to engage academic and related staff groups that fits

11 with their institutional culture and is therefore likely to lead to the kind of continual professional

12 learning (CPL) and positive change that will be both valued and valuable in academia. Furthermore,

13 we believe that AL might offer productive ways forward for the further evolution of academic

14 development work, especially, perhaps, in research-intensive settings.

Key Words: Action Learning, academic development, facilitation, change.

Corresponding Author: Dr. Claire Stocks, Centre for Excellence in Learning and Teaching, University of Central Lancashire, Preston, PR1 2HE.

20 E-mail: CStocks3@uclan.ac.uk 


\section{Introduction}

2 Action learning ( $\mathrm{AL}$ ) is, on the one hand, a well-established and proven mode of pursuing change in organisational settings, yet, on the other, does not appear to have been as prominent in academic development work as might be expected. Despite the fact that Reg Revans, commonly held to be the founding father of AL, cited his experiences as a Physicist at the University of Cambridge as seminal in his thinking about AL, the approach does not generally seem to have found favour in Higher Education (Bourner, 2011), and it may be that this stance has carried over into academic development. Tom Bourner, in a retrospective of his own involvement with AL, suggests that, "In practice, much of higher education seems to favour didactic instruction by academics as experts. Action learning is challenging to didactic instruction and to experts. It offers an alternative to programmed learning from lectures and textbooks. For this reason, AL has often met a hostile response within universities." (52) Nevertheless, Bourner sees things changing, and over the last 25 years, "experience also suggests that there are areas within higher education with doors that are open to action learning." (53).

In this paper we argue that AL does have something significant to contribute to academic development in Higher Education, in particular to research-intensive institutions, whose culture and ways of working are perhaps more aligned with AL approaches. We not only illustrate contrasting applications of AL for specific development purposes (via two case studies), but contextualise it as a development approach that potentially aligns well with broader shifts in the contemporary academic development landscape. This leads to questions concerning the on-going changes in expectations, identities and roles of academic developers (staff who are often, and certainly in the cases presented here, not appointed as academics) and how best to understand and negotiate these factors.

\section{What is Action Learning?}

Action learning fosters learning in the workplace and is "a continuous process of learning and reflection, supported by colleagues, with an intention of getting things done" (McGill and Beaty, 1999, p.21). For this reason, it has typically featured in management and business studies (cf Bourner, 2011), but now also is being explored more widely, including in health sciences (e.g. Wales et al., 2013) educational leadership (e.g. Gunn and Lefoe, 2013) and with doctoral students developing their teaching practice (e.g. Regan and Besemer, 2009).

The emphasis always is on 'getting things done'; supporting reflection in order to reach new understandings and prompt changes in practice. This process of reflection and action is supported by peers in a 'learning set', which meets on a regular basis over (usually) a number of months for a predetermined amount of time (at least an hour, but often much longer). Sets offer a structured way of working in small groups: practitioners meet regularly and commit to sequentially sharing and exploring individuals' workplace-related problems, issues and ideas, which, in the context of our case studies (see below) is focussed on academic engagement with the practice of teaching and learning. The group does not offer advice but provides a confidential space within which each individual can discuss and explore their concerns freely. Sets also have a 'facilitator' (in the cases outlined here, this role is played by an educational/academic developer) who attends to, for example: the planning and process of set operation; time management; ensuring that each member has space and opportunity to contribute during each meeting; helping both the set, and each individual who makes up that set, to work constructively on the issue at hand, etc.

The process can be more or less structured, depending on the needs of participants. In general, some time is required for the designated presenter to explain the issue at hand, after which all participants discuss it for a period of time before a course of action is determined by the presenter. In the next meeting that presenter would generally be required to report on progress made (or not) 
before attention turns to a new issue that is generally offered by a new presenter from the set. This assumes that set members bring different challenges to the group (as in the UK case below), but this approach can be varied to support a group of members who are all working on the same issue (as for the Australian case below). The really important thing about the process is that it is sustained over time, involving iterative learning and reflection that lead to action, so that practice is improved and challenges are addressed in a timely fashion. This is action learning's defining feature.

\section{Action learning in two research-intensive universities}

We have used AL in research-intensive universities in both the UK and Australia. Representing complementary situations, the two cases typify many (primarily research-intensive) institutional contexts. Nowadays, it is entirely reasonable to expect that new academics embarking on a career should benefit from some sort of semi-structured guidance in developing their educational work (UK case study). Likewise, it is equally reasonable to expect that on-going pressures for institutional level change and adaptation in HE give rise to situations where established mid-career academics find they need to revisit long-established values and implicit assumptions about 'how things will or should work around here' (Australian case study). Our purpose through these two case studies is to explore the potential AL offers for positive experiences and valued outcomes in such circumstances, and to illustrate the versatility of AL in academic development. It is important to note that, in both cases, the academic developer/facilitator was not (at least contractually or by title) an academic member of staff. Sets comprised research students (in the UK) and academic staff (in Australia) working together with support - and, possibly, leadership - from a non-academic facilitator: a potentially novel situation that may need to be approached with some sensitivity, as we consider further below.

\section{UK Case Study: Supporting Graduate Teaching Assistants to gain recognition for their teaching} In the UK Russell Group University, AL was used to support Graduate Teaching Assistants (GTAs) to gain professional recognition for their teaching via the Higher Education Academy's (HEA) framework. A recognition scheme was devised around a work-based learning pedagogy - the GTAs were given support (through two workshops) to understand how we learn from experience, how AL works and how to write their claim for recognition (via the institution's accredited CPD framework). In addition, they were expected to attend a series of five AL sets over a period of seven months where they would take it in turns to present a teaching challenge for discussion. The first author designed and led the programme, with support from colleagues who helped to facilitate the learning sets.

The AL approach was chosen as being particularly appropriate for PhD students in the researchintensive setting, primarily because it allowed the participants to work on challenges that were current in their teaching practice, and to make changes that could be implemented almost immediately. PhD students are time poor, so their learning about teaching should be relevant and impactful. Moreover, their supervisors tend to focus them (quite appropriately) on their research and so they too had to be convinced that time spent on developing teaching was worthwhile and of benefit in the short, as well as longer, term. Finally, as a group of people who may well be entering the academic job market shortly, the learning set offered participants the opportunity to rehearse the language (and concepts) of learning and teaching, and to start to become comfortable with each. More so than workshops, the learning sets were dominated by the voices of the participants, with the facilitator introducing concepts, theories and terminology at the appropriate time. Discussions were then supported by suggested readings that were posted on the Virtual Learning Environment following the set meeting (and were expected to feature in the report offered by the presenter at the following meeting). 
The AL approach means that the participants defined the content of the meetings via the issues that they raised for discussion. The academic developer (as facilitator) has no real control over the subject matter under discussion. In reality, though, the participants tend to bring (contextualized to their own discipline and working environment) the fairly predictable concerns of a new teacher discussions around student motivation, diversity and the role of the teacher are common. Although formal evaluation of the scheme had not been carried out at the time of writing, the emphasis on 'getting things done' and reporting back to the set, means that, to a degree, a practice of 'peerevaluation' of changes in practice was built into the AL process. Each student presenter committed to action as part of their participation, and then reported on effectiveness of the change at the next meeting. This process gives the developer/facilitator some sense of the impact of the intervention. While talking through their issues, participants would often explicitly identify a change in their perception of the issue at hand, and would gratefully receive suggestions from other members of the set who had experience from very different disciplinary contexts. Members also noted that being asked challenging questions in a supportive space led them to reconsider practices or assumptions that they might have previously taken for granted. At the time of writing (and out of a total of 30 participants across four sets) 21 had gained their Associate Fellow (HEA) status, one had withdrawn from the process, three applications had been referred, and another five had not yet applied for recognition (generally for personal/family reasons).

\section{Australian Case Study: Development of a new (online, PBL) course in Law}

The Australian context is a strongly research-led institution (one of the top internationally rated universities in Australia) with the consequence that teaching typically is of secondary interest to many research-focussed academic staff. The Law College (Faculty) comprises two distinct academic staff populations, aligned with the traditional segregation of the discipline into 'scholarly academic study' and 'preparation for practice'. This segregation is most notably manifest in their different teaching programmes. A small in-house, non-academic staff group, CEIST (College Education and Innovation Support Team), supports operational and strategic educational development initiatives. Created and resourced originally under the auspices of the Faculty's practice-aligned sub-group, CEIST became a Faculty-wide support unit in the period immediately prior to the work reviewed here (Trevitt et al., 2017).

In 2011, the 'Faculty' committed to a new strategic initiative - to design and develop a new online, problem-based learning (PBL), graduate-entry, law degree (i.e. Juris Doctor). Two factors dominate the authors' perceptions regarding this initiative: (1) the desire to reach a student population currently under-represented (eg geographically dispersed; non-school leavers, etc), and (2) a pressing need to foster closer interaction between the 'two academic staff populations', and to appreciate and play to one-another's strengths more. That is, one staff grouping has generally been perceived as having its values and identities more closely aligned with scholarship and 'research' performance - especially as these attributes are understood traditionally in academia - while the other has been seen as more highly practice-oriented with a long history and established skill-base in online educational programme design and innovation, and with professional values and identities aligned accordingly. While CEIST was charged with an explicit leadership role in this new curriculum development initiative, with hindsight we'd suggest that the associated expectations were anything but explicit, and varied markedly across different groups, as we note further below.

As a new appointment within CEIST the third author was allocated a role of facilitator for an academic sub-group working on this new initiative. As the project matured, and his involvement increased, he was deployed further across other sub-groups within the project, culminating in a central role on a programme-wide advisory group. The project goals required facilitation of the 
development of several aspects of curriculum design, ensuring integration and cohesion across the programme as whole. Working with established mid-career academics, sometimes highly individualistic in approach, a key focus was on promoting a more collaborative, team-based approach to educational change and development. This is something that we now find ourselves able to suggest might well be perceived not only as counter-cultural, but also challenging in the way it can confront established academics' self-understandings (at least in our research-intensive setting). In addition, we'd suggest the process of engaging in sustained review and reflection on (educational) action for the purpose of systematic improvement - what we refer to above as AL's defining feature - can be experienced by such individuals as novel, if not potentially confronting. Characterised by "loss of expertise" or "expert becomes novice" (van Lankveld et al, 2017, 329) the care and commitment required to discuss pedagogical and curriculum details with peers, and hence work to establish a supporting vocabulary for that purpose, might be experienced as unduly demanding, even leading to resentment about the time and energy required - a perfectly reasonable reaction, given the pressures arising from wider institutional expectations (notably regarding research 'productivity'). The prevailing view of the relationship between teaching and research has been described as 'one filled with conflict that leads to tensions in one's identity as a teacher' in the review by van Lankveld et al $(2017,331)$.

Several defining elements help characterise the situation, which speak to the small-group facilitation process and participant roles. For example, elements uncommon to established (researchintensive?) academic work included:

- A new pedagogical and programme-level educational design, $\mathrm{PBL}$ and fully online, and aspiring to a spiral curriculum that results in a more integrated and coherent student experience;

- Academics coming together from the two largely distinct 'staff populations' within the 'Faculty', and needing to explore and establish mutually respectful ways of working together; and

- Academic sub-groups working in designated curriculum development teams under explicit leadership of non-academic support staff over an extended period with, for many individuals, no prior experience of having worked together, and consequent uncertainty concerning individual as well as group expectations.

AL was used in this case:

- as a lens through which to review the experience of the small-group team-based curriculum development activities; and,

- to help identify preferred processes, approaches and priorities for moving forward, given the need to develop many more courses within the new programme.

\section{Action learning as academic development in research-intensive settings}

Reflecting on our experiences we note a shift away from the type of work and the kind of role that we might have been expected (by ourselves and our colleagues) to undertake. In action learning, we may lead the set, but we are no longer 'the expert' at the front of 'a classroom'. In a learning set, the facilitator's voice is heard much less frequently than in a workshop, and our role is to encourage participants' reflection and action - action that they can take forwards for themselves in a sustained fashion. More so than ever, the developer's role is to make him/herself obsolete as we support colleagues to develop lifelong (reflective) learning habits rather than offering relatively isolated CPD events. These observations hint at the potential for AL as a powerful tool as the demands on academics and academic developers evolve. Graham Gibbs (2013) has noted that academic development has not, and does not, stand still but that there have been shifts in focus, emphases and practices over time. In the years since Gibbs's article was published, we contend there have been further changes within Higher Education, along with mounting pressures for yet more change, 
and that using AL by leveraging the themes below might further embed the work of academic development (perhaps especially in research-intensive settings).

\section{From a focus on talking at teachers to a focus on talking about teaching}

Supporting academic colleagues to discuss teaching is perhaps more powerful than we might first imagine. In their investigation into leadership of teaching in research-intensive departments, Gibbs, Knapper \& Piccinin found that "developing excellent teaching and maintaining that excellence involved a great deal of talking about teaching" (2008, p. 422). The implication is, perhaps, that in less research-intensive institutions, where progression is potentially more clearly connected to teaching, there may be more time and attention dedicated to the development of teaching, and less need to carve out time and space for teaching conversations. Nevertheless (and regardless of the type of institution involved), Roxå and Mårtensson suggest that higher education should be problematized in order to expose the tacit values and assumptions that drive learning and teaching (and therefore academic development) for good or ill.

Academic teachers need to talk to each other about their experiences of teaching and student learning and about their everyday life inside higher education organisations. In effect, this implies a counter discourse: academic teachers, anchored in their everyday experiences and in the values guiding their disciplinary training, fuel an alternative discourse about academic teaching and student learning. Our job as academic developers is to scaffold these conversations to become informed and critical and ultimately transformative.

(2017, p. 9)

AL is one way that we can support academic staff to explore the challenges of their everyday academic and teaching work and to unpack the implicit assumptions and values that exert pressure on their practice.

Gibbs et. al. argue that, while forums for the discussion of research are already fairly common in research-intensive settings, "new forums were needed ... to build a community of practice about teaching" (2008, p. 422). Forums that 'talk about teaching' could well be initiated through or built around AL sets, thereby enabling academics (who are used to posing and discussing research questions) to formulate and work on teaching questions. In the GTA (UK) case outlined above, a structured induction via $A L$ is explicitly intended to better equip new or intending academics to not only participate in but to lead constructive discussions around learning and teaching, both at the time and into the future.

\section{"From agents of change to partners in arms" (Debowski, 2014, p. 50)}

While Bourner noted that didactic approaches run counter to the philosophy of AL, the work of an AL set might appeal to research-active academics, whose expertise in identifying questions, investigating problems and refining solutions can all be brought to bear in a teaching context. The engagement of all of the participants in the learning set, and the role of the developer/facilitator as leader of the process means that the work of AL is collaborative (see Day and Harrison, 2007, p. 369). Shelda Debowski argues that "the notion of an [academic developer] as an agent who assists others to think more deeply offers considerable strength as we explore our future roles and identities. To do so, we will need to progressively move away from a centralist, expert identity to a more open, adaptive, reflective partnership model that enables us to be invited into more localized groups and to accommodate and recognize their specific needs" (2014, p. 55).

Further to being 'partners in arms', our case studies demonstrate how academic developers can find themselves expected to lead and model important aspects of academic work in their roles as learning set facilitator. The facilitator leadership role modelling in the Australian case arguably was 
somewhat more complex and multifaceted than in the UK, embracing as it did, a need to work with, and accommodate, a wide range of well-established (negative as well as positive) motivations amongst academic colleagues. An explicit development perspective was adopted, seeking to nurture in others the behaviours and dispositions on display, even while endeavouring to ensure strategic organisational expectations were met in a timely way. With the benefit of hindsight, we are now becoming alert to a range of questions regarding the adequacy of shared understanding of (as well as preparation for) the facilitator-leader role that had been assigned to (non-academic) CEIST educational developer staff. At the same time, we are becoming alert to the way in which this sort of situation is becoming increasingly common in the HE sector.

In a study of the expansion of professional identities in higher education, Whitchurch (2012) explored various models of multi-professional teams comprising academic as well as professional ('third space') staff, and observed:

- that "academically oriented project roles [are now] explicitly recognised and embedded in institutional structures" (p. 105);

- there is a need for a "role of translator between different internal constituencies" (p. 111), and

- 'that the binary distinction between 'academic' and 'non-academic' roles and activities may no longer be clear-cut" (p. 99).

Her study stopped short of exploring leadership-identity issues, however. As our experiences have highlighted, it is now quite possible for non-academics to find themselves being asked to lead groups of academics and, possibly, to model and inculcate a distributed approach to educational leadership (cf Day and Harrison, 2007; Gunn and Lefoe, 2013). Where well-established academic participants find this novel, then there is potential for challenges to arise, perhaps involving "negotiation of meaning, identity and power" (eg see Jørgensen and Keller, 2005).

\section{From a focus on bringing about change to a focus on continued improvement}

Action learning for academic development purposes, as suggested above, shifts the emphasis from decontextualized workshops focussed on 'teaching', to facilitating discussion between peers (academic and/or more broadly) in support of solving challenges that participants have brought to one-another's attention. One practical benefit, therefore, is that the challenges, issues and need for change come not from the facilitator/developer, but from participants. As we know, "people always see imposed change as something to be resisted but change that they have identified for themselves they get interested in and are keen on" (Land, 2001, p. 12). Furthermore, as Gibbs et al. note, "academics are well trained in spotting weak arguments, especially weak arguments for change" $(2008$, p. 422). In terms of supporting change, then, AL removes one of the main barriers because participants have already recognised the need for change themselves. This is arguably of particular significance in more traditional, research-intensive settings, where the predominant culture tends to be, in Land's conceptualisation, collegial, with high levels of autonomy and where decisions imposed from the centre may well be exposed to dissent $(2001$, p. 7$)$. In such a culture, academic development tends to be more effective where it is discipline-specific and person-focussed, led by developers with a reflective practice orientation. The links with AL are clear - issues to be addressed come from participants and spring from their everyday practice.

\section{From a focus on supporting teaching to a focus on leading continuing learning}

Gibbs (2013) notes a shift of focus from teaching to learning in that developers now tend to problematize the assumed connection between the two. We envisage a further step, whereby the emphasis is more sharply on CPL - via reflective practice, enabled perhaps via AL - in favour of, say, disseminating best practice in teaching. Brew and Boud (1995, p. 268) contend that "the relationship between teaching and research can never be satisfactorily demonstrated", and this has led research- 
active academics to view their teaching as quite separate from their (more prestigious) research work. Nevertheless, Brew and Boud argue that "learning...is the vital link between research and teaching. It is a shared process in these two enterprises" and, furthermore, "it is not only through research that teachers learn in deep ways. Reflective professional practice also affords this opportunity" (p. 270).

How best to lead such CPL and associated reflective academic practice - and so harness learning as the link between teaching and research to promote an integrated way of academic being - remains an ongoing and urgent question. A question that, for us, has cast $A L$ as one possible solution. Nixon and colleagues (1998, p. 282-3) have called for "academic workers ... to become serious about [their] own professionalism" and to take responsibility for their own "professional self-development" ... "preferably at department or faculty level" if we are to avoid "the absurd situation, whereby 'nonacademics' are given responsibility for developing 'academic' professionalism". While our Australian case may have what for Nixon and colleagues is the redeeming characteristic of being a faculty-level initiative, both our cases illustrate (what for these authors at least) is the challenging paradox whereby non-academics are expected to play a leadership role in academic development. If/as institutions more actively and systematically seek out and prove suitable ways to structure, support and enhance leadership for academic CPL then such difficulties could recede. Where AL (or AL-like) processes are implicated, who, if anyone, could or should take on the role of facilitator appears to be an open question (see also Holmes, 2008).

\section{Conclusion}

We have been impressed not only by the variety of ways in which AL has and might be used in academic development, but also how it helps us to think further about our roles as 'third space' professionals. Our experiences suggest that AL offers one way for university academics and professional staff both to prepare for and accommodate the relentless (re-)negotiation (eg of motivation, meaning, values, power and identity) required as universities continue to adapt to changing societal expectations. The on-going pressures for change and institutional adaptation suggest that team-based educational development projects of the sort undertaken in the Australian case are likely to become more, rather than less, common. In turn, that implies a desire for better preparation at the outset of a career ( $c f$ UK case) involving a more widespread and explicit (not implicit) understanding of academic and related professional identities (cf van Lankveld, 2017) and the role played by distributed leadership (cf Day and Harrison, 2007; Gunn and Lefoe, 2013). In our particular institutions, aspects of AL seem to sit well with the culture, and how our participants think about their work and roles. It offers a devolved model of expertise, and makes an explicit connection (through learning) between research, teaching and development. AL is closely connected to reflection and reflective practice and that might make it more or less likely to work in certain contexts (cf. Land, 2001). While a central role was played by non-academic 'third-space' developers as facilitators and leaders of on-going conversations supporting development work here, the longterm veracity of such an approach is unclear, and should benefit from others' insights in similar contexts.

\section{References}

Bourner, T. (2011). Action learning over time: an ipsative enquiry. Action Learning: Research and Practice, 8, 43-56.

Brew, A., \& Boud, D. (1995). Teaching and research: Establishing the vital link with learning. Higher education, 29, 261-273.

Day, D. V., \& Harrison, M. M. (2007). A multilevel, identity-based approach to leadership 
development. Human Resource Management Review, 17(4), 360-373.

Debowski, S. (2014). From agents of change to partners in arms: the emerging academic developer role. International journal for Academic Development, 19, 50-56.

Gibbs, G. (2013). Reflections on the changing nature of educational development. International Journal for Academic Development, 18, 4-14.

Gibbs, G., Knapper, C., \& Piccinin, S. (2008). Disciplinary and contextually appropriate approaches to leadership of teaching in research-intensive academic departments in higher education. Higher Education Quarterly, 62, 416-436.

Gunn, C. \& Lefoe, G. (2013). Evaluating action-learning and professional networking as a framework for educational leadership capacity development. International Journal for Academic Development, 18, 45-59.

Holmes, Mary (2008). What do set facilitators bring to the party? (And do we need them?). Action Learning: Research and Practice, 5(3), 249-253.

Jørgensen, K. M., \& Keller, H. D. (2005). The role of identity and power in organizational learning. Paper presented at RWL4 International Conference on Researching Work and Learning, Sydney, Australia, 11-14 December.

Land, R. (2001). Agency, context and change in academic development. International Journal for Academic Development, 6, 4-20.

McGill, I., \& Beaty, L. (1999). Action Learning: a guide for professional, management \& educational development. London: Kogan Page.

Nixon, Jon, Beattie, Mary, Challis, Maggie \& Walker, Melanie (1998). What does it mean to be an academic? A colloquium. Teaching in Higher Education, 3(3), 277-298.

Regan, J. \& Besemer, K. (2009). Using action learning to support doctoral students to develop their teaching practice. International Journal for Academic Development, 14, 209-220.

Roxå, T., \& Mårtensson, K. (2017). Agency and structure in academic development practices: are we liberating academic teachers or are we part of a machinery supressing them? International Journal for Academic Development, 22(2), 95-105.

Trevitt, Chris, Steed, Aliya, Du Moulin, Lynn, \& Foley, Tony (2017). Leading entrepreneurial elearning development in legal education: A longitudinal case study of "universities as learning organisations". The Learning Organization, 24(5), 298-31.

van Lankveld, Thea , Schoonenboom, Judith, Volman, Monique, Croiset, Gerda \& Beishuizen, Jos (2017). Developing a teacher identity in the university context: a systematic review of the literature. Higher Education Research \& Development, 36(2), 325-342.

Whitchurch, C. (2012). Expanding the parameters of academia. Higher Education, 64, 99-117.

\section{Author Biographies}

Dr. Claire Stocks is Academic Development Lead at the University of Central Lancashire. Her research interests are in supporting the development of novice academics and the use of work-based learning in academic development.

Dr. Chris Trevitt is an Educational Design Consultant at the ANU College of Law. He has enduring interests in professional learning and educational change, assessment perspectives on curriculum, and use of portfolios.

Dr. Joseph Hughes is an Educational Developer Manager at the ANU College of Law. Praxis and collaborative learning, and how they intersect with technology-enhanced learning, are fundamental to his work practices and research interests. 